\title{
Do racismo à valorização da diversidade na educação brasileira
}

\section{From racism to valuing diversity in Brazilian education}

\author{
BIANCO, Marcos Wander ${ }^{1}$ \\ RETT, Valéria ${ }^{2}$ \\ COELHO, Patrícia M.F. ${ }^{3}$
}

\begin{abstract}
Resumo
Este artigo aborda a evolução do racismo e a valorização da diversidade na educação brasileira. O processo histórico que investiga a gênese do racismo, suas implicações nas questões sociais e o sofrimento psíquico dos negros até sua integração nas sociedades, traz relevante contribuição para explicar as tendências discriminatórias na educação, assim como revela aspectos que orientam a criação de políticas para a superação do racismo na sociedade brasileira, especificamente sendo analisado o contexto da educação escolar. Os resultados mostraram que o combate ao racismo tem início com o reconhecimento do outro e de suas particularidades, que nos são distintas, porém podem ser complementares, além da noção de que a diversidade revela traços culturais brasileiros que devem ser legitimados como parte integrante da cultura e de sua evolução, tendo a educação o papel de consolidar e disseminar as características socioculturais.
\end{abstract}

Palavras-chave: racismo, diversidade, educação.

\begin{abstract}
This article discusses the evolution of racism and value diversity in Brazilian education. The historical process that investigates the genesis of racism, its implications on social issues and the psychological suffering of blacks until their integration into societies, brings a relevant contribution to explain the discriminatory tendencies in education, as well as reveals aspects that guide the creation of policies for the overcoming racism in Brazilian society, specifically by analyzing the context of school education. The results showed that the fight against racism begins with the recognition of the other and their particularities, which are different, but can be complementary, in addition to the notion that diversity reveals Brazilian cultural traits that must be legitimized as an integral part of culture and its evolution, with education having the role of consolidating and disseminating socio-cultural characteristics.
\end{abstract}

Keywords: racism, diversity, education.

\section{Introdução}

Este artigo aborda o racismo no Brasil pela perspectiva da transformação na identidade da população a partir da valorização da diversidade. Há um processo socio-histórico que se representa pela formação populacional

\footnotetext{
${ }^{1}$ Mestrando. Departamento de Educação. Universidade Ibirapuera. E-mail de contato: marcosbianco@terra.com.br

2 Mestranda. Departamento de Educação. Universidade Ibirapuera. E-mail de contato: pravaleria@hotmail.com

${ }^{3}$ Coordenadora e Professora Titular do Mestrado em Ciências Humanas da Universidade Santo Amaro e Professora Titular do Programa de Mestrado e Doutorado em Educação da Universidade Metodista de São Paulo. E-mail de contato: patriciafariascoelho@gmail.com
} 
bastante miscigenada desde a constituição da sociedade, formada por etnias de indígenas, portugueses, negros e, posteriormente, por espanhóis, alemães, italianos, árabes e japoneses.

A Pesquisa Nacional por Amostra de Domicílios (PNAD) do ano de 2015 apresenta essa realidade por meio da autodeclaração dos brasileiros sobre cor ou raça, em que se destacam 45,22\% de brancos, 45,06\% de pardos, $8,86 \%$ de negros, $0,47 \%$ de amarelos e $0,38 \%$ de indígenas. Essa distribuição é a mais atual utilizada no País que, de acordo com dados do IBGE (2019), apresenta população de 210.827.220 pessoas em dezembro de 2019.

Gomes (2011) explica que, nos estudos sobre relações raciais no Brasil, a composição étnico-racial pode ser interpretada sob algumas abordagens, tais como econômica, política e sociológica, sendo que as interpretações levam em consideração a soma das categorias de negros e pardos para caracterizar a população negra no Brasil. A autora comenta que essa definição determina a sua identidade:

Como toda identidade, a identidade negra é uma construção pessoal e social e é elaborada individual e socialmente de forma diversa. No caso brasileiro, essa tarefa torna-se ainda mais complexa, uma vez que se realiza na articulação entre classe, gênero e raça no contexto da ambiguidade do racismo brasileiro e da crescente desigualdade social (Gomes, 2011, p. 110).

Assim, compreende-se que estudar o racismo no Brasil não é simples, uma vez que são encontrados alguns aspectos que se relacionam. Todavia, houve movimentos no País a fim de reduzir as desigualdades que culminam no racismo, com ênfase no respeito à diversidade como forma de coibir a discriminação, não somente de raça e cor, mas de gênero, etnias, idade, saúde, dentre outras.

Estabeleceu-se um conjunto de diferenças individuais que abarcam grupos sociais para discutir a importância da diversidade na sociedade brasileira, a fim de reduzir as desigualdades e produzir formas de combate ao racismo. Contudo, percebe-se que a diversidade é um tema que vem sendo mencionado com força cada vez maior e requer reflexão sobre o seu contexto e aplicação, uma vez que se trata de modificar e constituir identidades para uma sociedade.

Guareschi (2018, p. 409) argumenta essa necessidade de se falar em diversidade:

A urgência em abordar a temática da diversidade se dá em razão de que, mesmo diante de práticas pautadas no respeito às diferenças, ainda no presente encontramos lógicas normalizadoras pautando ações direcionadas a populações específicas, seja no âmbito da saúde, da educação, da assistência, da segurança, da raça e da sexualidade, cujas intervenções, não raro, tendem a produzir, como efeito, sujeições às normas (Guareschi, 2018, p. 409).

Para Guareschi (2018), o debate da diversidade deve promover o acesso e a efetivação de direitos, por um olhar multiprofissional, que tem de considerar a pesquisa e a prática que saiba lidar com as diferenças entre os sujeitos na garantia de seus direitos e satisfação às suas necessidades. E desse argumento surge o questionamento desta pesquisa: Como se deu a evolução do debate sobre o racismo para emergir o respeito à diversidade na educação brasileira? Constitui essa uma relação possível?

O objetivo é identificar a contribuição do discurso da diversidade na educação brasileira para o combate ao racismo e à discriminação nas escolas, a partir dos objetivos específicos:

a) analisar o processo histórico de inserção do negro na sociedade brasileira;

b) identificar a construção social do racismo;

c) mostrar os elementos psicanalíticos do racismo;

d) entrelaçar os elementos sociais e psicanalíticos do racismo com a educação e a diversidade. 
Foi realizada uma pesquisa qualitativa a partir de revisão bibliográfica e análise de conteúdo das publicações sobre racismo, discriminação e diversidade no Brasil, assim como sua inserção na educação.

A relevância deste estudo configura-se pela necessidade de explicar os aspectos psicanalíticos que podem ser extraídos para clarificar a questão do racismo na educação, uma vez que, trazidos à compreensão, podem resultar em soluções consistentes para os problemas sociais que estão envolvidos no contexto educacional brasileiro.

\section{Do racismo ao respeito à diversidade}

Nesse arcabouço teórico, aborda-se a evolução do racismo desde a sua origem nas sociedades, incluindo o cenário brasileiro, partindo de um contexto histórico de seu surgimento e consolidação pela adoção dos conceitos psicanalíticos Freud-lacanianos para explicar sua gênese e efeitos na educação até chegar à evolução da noção de diversidade como forma de combate ao racismo.

\subsection{Processo histórico: integração do negro nas sociedades}

A história do racismo inicia-se pela migração de pessoas para outros países, contudo, no Brasil, data desde o descobrimento, a começar pelos indígenas. Por esse motivo, primeiramente, é preciso discutir o conceito de raça e racismo como tentativa de contextualizar o processo histórico que norteia a integração do negro.

Almeida (2019) explica a raça como um modo de classificação, que iniciou com plantas e animais e posteriormente alcançou os seres humanos. Contudo, o conceito de raça relacionado a pessoas reflete elementos como contingência, conflito, poder e decisão, o que faz o autor pensar no âmbito dos relacionamentos e no contexto histórico em que se apresenta. E nesse ínterim, surge o conceito de racismo, especialmente o racismo moderno, que apresenta a inferioridade de raças como aparato ideológico para a opressão colonial, sendo apresentado como uma característica étnica-cultural, que engloba a questão da identidade, sendo atrelada à geografia, à religião, à língua e aos costumes, assim iniciando um processo discriminatório.

Almeida (2019) ainda continua sua argumentação destacando o conceito de racismo e de discriminação racial como uma relação de poder sobre o outro:

É uma forma sistemática de discriminação que tem a raça como fundamento, e que se manifesta por meio de práticas conscientes ou inconscientes que culminam em desvantagens ou privilégios para indivíduos, a depender do grupo racial ao qual pertençam [...] a atribuição de tratamento diferenciado a membros de grupos racialmente identificados (Almeida, 2019, p. 1).

Pereira (2001) argumenta sobre o que se define por racismo e contextualiza sua explanação a partir de uma perspectiva histórica do etnocentrismo, algo que ele associa ao racismo:

Para principiar, o racismo não é, nem de longe, algo que ressurge das cinzas da última conflagração mundial. Até onde se pode documentar, constitui um fenômeno tão velho quanto a própria história da humanização, se for encarado como uma das múltiplas faces do conhecido e universal etnocentrismo, componente que é das experiências históricas de todos os povos. Essa universalidade do fenômeno talvez se possa explicar pelo que os teóricos funcionalistas denominavam de função positiva do etnocentrismo: seria ela indispensável para criar laços morais de solidariedade social entre indivíduos do mesmo grupo, fixar fronteiras simbólicas e reais entre populações, singularizar povos, enfim, dar a identidade grupal pela qual os indivíduos a si mesmos se reconhecem e reconhecem os demais, os "outros" (Pereira, 2001 p. 169).

As definições propostas por Almeida (2019) e Pereira (2001) convergem para uma explicação do racismo como evolução da história das sociedades no mundo e no Brasil, em que a inserção e posterior exclusão do negro são 
faces de uma mesma perspectiva histórica na evolução dos fenômenos econômicos e políticos, com desdobramentos nos campos social e educacional.

De acordo com Domingues (2019), a história do negro no Brasil sofreu uma lacuna no período pós-abolição da escravidão, em que houve um movimento de inserção do branco, do imigrante, do operário e o esquecimento do não branco. $O$ autor questiona se tal condição foi fortuita ou com intencionalidade de exclusão. Destaca-se que a realidade analisada foi o estado de São Paulo, que se apresentava com maior perspectiva no campo da industrialização.

Domingues (2019) ainda considera que o processo histórico do racismo abarca sua construção social, em que os negros foram negados não apenas por suas condições de classe, mas manipulados pela dominação dos brancos, mostrando-se como vencedores, o que indicava um racismo institucionalizado antinegro que legitimou o processo de branqueamento no Brasil.

Bento (2009) enfatiza que o branqueamento pode ser explicado por aspectos identitários e de projeção do negro sobre o branco a partir da crítica de que essa noção foi produzida pelos brancos de forma a negar a competência dos negros e, ao mesmo tempo, de obter privilégios segundo os seus interesses. Assim, a contribuição dessa autora versa sobre a perspectiva de análise da discriminação no Brasil, pois se considera o racismo como um problema do negro, excluindo o branco da cena racista. Essa negação da participação do branco como causador da discriminação também é uma forma de racismo.

Henrique (2007) descreve o racismo no Brasil como um processo escondido, e que é difícil de ser trabalhado devido à grande miscigenação existente. A mescla das raças e a evolução da sociedade com maior participação do negro modificou o contexto histórico. A partir do momento em que se reconhece que o não branco, como era antes considerado, passa a ser mais atuante e torna-se a maioria da população, há um resgate do valor do contexto escravista, pois havia destacada atuação do negro/escravo enquanto ser social no processo histórico do racismo.

Aqui se percebe o início do discurso que inclui o negro na sociedade brasileira e retrata um processo de resgate do seu valor na constituição social do País. Porém, a complexidade para a abordagem desse tema reflete na participação social do negro frente às outras perspectivas que são parte da análise até se chegar à valorização da diversidade. Para isso, é preciso considerar as questões sociais relacionadas ao racismo no Brasil.

\section{Questões sociais do racismo: breves notas}

Almeida (2019) faz uma análise do racismo estrutural, explanando que esse é um elemento integrante da organização política e econômica da sociedade, ou seja, que qualquer tipo de racismo é, em si, estrutural, uma vez que reproduz os formatos de desigualdade que permeiam a sociedade, incluindo a violência. $\mathrm{O}$ autor ressalta também que, para se abordar o racismo, é necessário discutir o conteúdo da teoria social, pois dela faz parte, e não há como dissociar uma análise da outra.

Silva e Souza (2017) explicam as questões sociais relacionadas ao racismo expondo que o pensamento políticoideológico sobre os negros no Brasil, e em alguns lugares do mundo, em sua evolução, apresentam idiossincrasias para abordar as más condições sociais e de vida, assim como a marginalização econômica e política dessas populações. Os autores argumentam que houve uma naturalização da exclusão social e a marginalização dos negros, sendo estes considerados limitados e inadequados para o trabalho e convivência familiar e social (por serem considerados sem laços estáveis). 
Para Domingues (2019), a luta de raças é confundida com o parâmetro econômico, uma vez que recai sobre as classes sociais e na inserção do negro nessa classificação, o que se dá no âmbito das oportunidades de trabalho e estudo.

A análise proposta por Pereira (2001) mostra-se rica ao explorar o cenário das sociedades historicamente escravocratas, cuja construção dos desiguais oferece o surgimento de uma hierarquização racial, desfavorável aos diferentes. Também Pereira (2001) evidencia o movimento migratório como uma questão social do racismo, uma vez que há relação de sociedades diferentes, com produtos sociais e culturais resultantes da migração.

Koltai (2008) analisa a identidade social do negro ao inferir que sua construção ocorre num contexto de relações de poder, resultando na criação de três formatos de identidade com distinção em sua origem:

1) Legitimadora: constituída por instituições dominantes da sociedade, com o fito de racionalizar e legitimar sua dominação sobre os demais atores sociais;

2) De resistência: constituída por atores sociais em desvalorização ou estigmatizados pela lógica dominante, que necessitam adotar os princípios estrangeiros ou contrários a tal lógica em que estão inseridos, caracterizando-se como desiguais;

3) Identidade-projeto: constitui-se dos atores sociais que constroem uma identidade nova a partir da cultura, que tem como fundamento redefinir a posição na sociedade e transformar/adequar a estrutura social.

A autora explicita que os tipos de identidade dependem de um contexto histórico para definir sua essência, assim como da teoria social, como forma de se legitimar ou tornar racional sua dominação, mas há como se modificar os tipos a partir da perspectiva de evolução social.

Nesse ínterim nasce o ambiente que propicia o surgimento da diversidade, analisado por Pereira (2001), como um conceito cujo controle é político e ideológico. Todavia, expressam distintos tipos de sociedade, em que há intolerância até à liberdade. No primeiro tipo, há restrição em se falar de diversidade, pois sobressaem relações de subordinação/dominação sobre a desigualdade; no segundo tipo, há presença da diversidade, e essa relação é superposta, a exemplo do Brasil. Demarca que essa associação recai mais sobre o negro, uma vez que imigrantes e outras correntes étnicas são tidos como contribuintes do processo sociocultural do País.

Pereira (2001) ainda esclarece que a participação do negro na constituição cultural de uma sociedade apresentou evolução na década de 1920, colocando-se em patamar de igualdade em relação ao imigrante e outros atores constituintes do recorte sociocultural, o que auxiliou na consolidação do conceito de diversidade. Porém, como grupo racial, foi estereotipado, transformando-se em vítima de desigualdade social, e assim permaneceu no cenário brasileiro, pois a abordagem cultural menosprezava as características biológicas e estruturais socioeconômicas. Assim, quando se retoma a questão do estrato social, há uma regressão na perspectiva do negro na sociedade brasileira, o que ocorre na década de 50, em São Paulo, a partir de influência marxista nas condições de produção:

O caso da população negra mostra, portanto, com ênfase, que diversidade não é necessariamente sinônimo de igualdade/desigualdade. A diversidade, que se situa prioritariamente nos domínios da cultura, por ser enriquecedora do convívio humano e do país, deve ser respeitada e até estimulada, enquanto a desigualdade, que se desenha basicamente no plano da estrutura socioeconômica e se infiltra pela psicologia individual e pelo imaginário social, por ser empobrecedora da condição humana e da nação, deve ser repelida, eliminada (Pereira, 2001, p. 172). 
Com essa explanação, compreende-se que o contexto cultural que deu origem à valorização da diversidade perdeu sua significância na sociedade, levando consigo a perda de identidade, ou a sua negação, como se pode analisar pela perspectiva da psicanálise.

\section{Breve análise psicanalítica do racismo}

A abordagem da psicanálise Freud-lacaniana contribui para a exploração do racismo em sua gênese e explica a subjetividade relativa aos seus desdobramentos nas sociedades. De acordo com Barros (2014), são elencados como conceitos psicanalíticos, pertinentes ao racismo, a negação, que é explicada por Laplanche e Pontalis (2000) como "o processo pelo qual o sujeito, embora formulando um dos seus desejos, pensamentos ou sentimentos até então recalcado, continua a defender-se dele negando que lhe pertença" (Laplanche \& Pontalis, 2000, p. 113), e o recalque, ambos trabalhados em Freud (2006) a partir de ênfases das paridades percepção/representação, objetivo/subjetivo.

Freud (2006) explica o fenômeno do recalque por meio de seu relato sobre pacientes com histeria, nos quais aparecia um desejo violento, distinto de seus outros desejos mais comuns, incompatível com aspirações morais e estéticas de suas personalidades, causador de conflitos, cuja luta interna era sucumbir ao recalque da representação presente na consciência, o que trazia em si o desejo inconciliável. Tal representação era esquecida e expulsa da consciência junto com as lembranças.

A caracterização do recalque refere-se à incompatibilidade entre a ideia e o ego do doente, e os desejos individuais, éticos, e outros, constituem as forças recalcantes. O recalque consiste, portanto, numa forma de proteger a personalidade psíquica para evitar o desprazer ante a aceitação do desejo impulsivo ou do conflito prolongado.

Bento (2009) também postula que dentre os fenômenos que podem ser analisados na psicanálise para tentar compreender o racismo, destaca-se a noção de narcisismo que, segundo o dicionário Houaiss (s.n.), é o "amor pela própria imagem". Para a psicanálise, a noção de narcisismo relaciona-se à de autoerotismo: no narcisismo é o ego, como imagem unificada do corpo, o objeto da libido narcísica, e o autoerotismo é definido, por oposição, como a fase anárquica que precede essa convergência das pulsões parciais para um objeto comum: "Temos de admitir que não existe no indivíduo, desde o início, uma unidade comparável ao ego; o ego tem de passar por um desenvolvimento. Mas as pulsões autoeróticas existem desde a origem; alguma coisa, uma nova ação psíquica, deve, pois, vir juntar-se ao autoerotismo para dar o narcisismo". Freud estabelece a passagem do autoerotismo para o narcisismo: “'[...] as pulsões sexuais, até então isoladas, reuniram-se agora numa unidade, e simultaneamente acharam um objeto'; esse objeto é o ego" (Laplanche \& Pontalis, 2000, p. 48).

O narcisismo e o ódio narcísico, o medo "do outro", que partem da projeção para a construção da discriminação racial, sempre são direcionados do branco ao negro. Ela explica o ódio narcísico a partir do modelo de si mesmo, que abrange o ego, que ama tudo aquilo que consegue refletir como parte de si e odeia o diferente, pois é reconhecido pelo ego como o lado ruim.

Já o medo do outro encontra explicação nas epidemias que ocorreram na Europa nos séculos XVI e XVII, especialmente na Itália, França e Inglaterra. Naquela situação, houve a busca por culpados, sendo considerados como suspeitos todos os que não eram provenientes das comunidades, ou seja, os estrangeiros e diferentes, para os quais foi direcionada a agressividade coletiva, emergindo assim o racismo.

Koltai (2008) complementa a ideia trabalhada por Bento (2009): 
Enquanto manifestação do mal-estar na civilização, o racismo tem a ver não apenas com um determinado dispositivo social como também com a estrutura do sujeito, razão pela qual pode ser abordado pela psicanálise como um sintoma social e histórico, significado pelo Grande Outro, algo capaz de mudar com o tempo, acompanhando as transformações do Grande Outro - tanto no plano pessoal como no coletivo (Koltai, 2008, p. 66).

Todavia, o medo do outro também pode expressar uma condição ou sentimento de ameaça, de limitação frente ao seu potencial, o que gera a repressão e a negação. Barros (2014) esclarece, sobre essa perspectiva, que o processo de aceitação ou negação associa-se a um julgamento intelectual, uma vez que se refere à forma como a pessoa percebe o mundo e experiencia as situações conforme aquilo que foi recalcado ao longo desse período: "Em outras palavras, ao passo que o sujeito recalca, reprime ou exclui o que lhe é insuportável, estrutura-se de maneira tal que tudo isto se atrela, para ele, à própria constituição da realidade, de sua apreciação do dentro e do fora" (Barros, 2014, p. 123). Esse fenômeno revela um possível sofrimento psíquico, compreendido como uma consequência da aceleração do processo substitutivo, fruto da capitalização do saber sobre o mal-estar, é a produção de um sofrimento cada vez mais refratário à singularização. Nessas trocas de saber, acrescenta-se um mais-de-gozo, em tudo similar à agregação de valor próprio da mais-valia (Dunker, 2004, p. 98).

Koltai (2008) é resgatado pela compreensão que favorece o sofrimento psíquico causado pela questão do ódio ao negro e ao estrangeiro:

O estrangeiro provoca, sempre, movimentos de alma: amor, ódio, temor, "amódio", e, em nossos dias, oscilamos entre o fascínio que ele exerce - é o caso do exotismo - e o horror que provoca em nós - é o caso do racismo. Objeto identificatório e contra-identificatório, o sujeito nunca permanece indiferente perante o estrangeiro, como se tivesse de fazer existir fora de si algo que lhe é interior. E se o Outro fosse eu mesmo? (Koltai, 2008, p. 66).

Com essa breve análise das perspectivas psicanalíticas ancoradas na linha Freud-lacaniana frente ao racismo, percebe-se que o sujeito da sociedade, em nosso contexto, é o sujeito que pertence e se reconhece como membro de uma sociedade e analisado com o suporte da psicanálise nos fenômenos socioculturais e políticos. Rosa (2004) desenvolve um perfil de propensões de personalidade. Nesse encadeamento, há a formação da personalidade com tendências antidemocráticas, pois as diferentes concepções de sujeitos foram moldadas a partir da inserção nas dimensões social, cultural, econômica e estrutural que permeiam a sociedade brasileira, tendo ela uma evolução direcionada ao antinegro, que é envolvida pelos fenômenos psicanalíticos nesta pesquisa estudados.

Guareschi (2018) oferece desfecho a essa discussão sobre o sujeito frente às diferenças, pois a autora considera as dificuldades de se abordar diversidades e políticas de inclusão em análise da psicologia. Destaque-se a psicanálise Freud-lacaniana nesse contexto, pois há influências de teorias que recaem sobre os aspectos sociológicos, e mesmo que todas as perspectivas encontrem um ponto comum, que é o de garantir direitos, promover mudanças sociais e culturais, cada uma delas apresenta diferentes concepções do sujeito. Guareschi (2018) ainda alude que:

Nesse sentido, é pela heterogeneidade de posições teóricas e ontológicas nas áreas de saber e nas práticas profissionais que destacamos a importância de garantirmos que as situações de opressão e exploração não sigam acobertadas em nossa sociedade, de modo que, frente a elas, possamos reagir individualmente, ou em coletivos, buscando os mecanismos de que dispomos para promover a saúde mental e física de populações minoritárias, ou pessoas de diferentes raças, etnias, orientação sexual ou condição social (Guareschi, 2018, p. 410). 
Levando essa análise do sujeito em sua totalidade, do processo do racismo frente a condições sociais e psicanalíticas, chega-se a um aspecto estratégico para que haja o combate à discriminação e à continuidade da valorização da diversidade na sociedade brasileira, articulando a busca de uma nova perspectiva nesse discurso, a necessidade de se analisar a educação para a diversidade e a diversidade na educação.

\section{Racismo e educação no contexto brasileiro}

A educação é o elemento no qual se observa o racismo de uma perspectiva do fracasso escolar, que acontece em parte pela violência e pela evasão, devido ao preconceito presente no ambiente escolar e em suas políticas que, apesar do discurso, ainda se perpetua na sociedade brasileira.

Koltai (2008) oferece um panorama para a relação entre racismo e educação:

O racismo é muito mais que mera agressividade, ele é ódio do outro, ódio não por algo que esse outro tenha feito, e sim pelo que é. Enquanto doutrina, o racismo nasceu associado ao discurso da ciência; [...] Gobineau foi o primeiro a se servir desse termo em seu livro Essai sur l'inegalité des races humaines (1855) (Koltai, 2008, p. 67).

Tomando-se como princípio o fato de que a educação é formada em um contexto socioeconômico, político e cultural, novamente esses aspectos aparecem como um suporte ao racismo, embora o discurso atual seja o da diversidade, o do antirracismo, pois a figura do negro volta a se deslocar da desigualdade biológica para uma diferença cultural, a fim de se chegar ao conceito da diversidade.

Koltai (2008) ainda abarca o enfoque do sintoma, que é um limite de a pessoa agir e reagir às exigências temporais e desenvolver a crítica sobre o discurso atual, de uniformização do cotidiano, para assim superá-lo, alcançando não somente formas de pulsão, de desejo, mas de gozo, que a autora explica pela análise psicanalítica, utilizando Freud e Lacan em seu recorte da realidade:

Utilizo o conceito de gozo no sentido lacaniano, que remete àquilo que Freud chamou de "um além do princípio do prazer". Foi por meio desse conceito que Lacan deu conta da característica anfíbia do sintoma, unificando, através dele, libido e pulsão de morte, como se ambas estivessem unidas por um nó, a ponto de transformar aquilo que em Freud era uma oposição externa - libido de um lado, pulsão de morte do outro - numa antinomia interna, de modo que o conceito de gozo recobre tanto a satisfação como o mal-estar (Koltai, 2008, p. 67).

A explicação de Koltai (2008) traz o discurso da ciência como necessidade de buscar o bem ao outro, contudo sem reflexão sobre o que é esse bem e sem se colocar no lugar do outro, sem conhecer, pois não se é igual. E quanto maior a exigência da igualdade, mais o outro se posiciona como diferente. Assim, quanto maior a uniformização do discurso da ciência, mais haverá em relação à manifestação do diferente.

Dessa forma, o diferente é remetido à sensação de gozo. Inicialmente ligado ao prazer sexual, o conceito de gozo implica a ideia de uma transgressão da lei: desafio, submissão ou escárnio. O gozo, portanto, participa da perversão, teorizada por Lacan como um dos componentes estruturais do funcionamento psíquico, distinto das perversões sexuais. Posteriormente, o gozo foi repensado por Lacan no âmbito de uma teoria da identidade sexual, expressa em fórmulas da sexuação (Roudinesco \& Plon, 1998, p. 299). O fenômeno do gozo pode fazer o sujeito odiar o que é diferente dele, uma vez que ameaça a forma de gozar socialmente idealizada na ciência. A autora ainda complementa: "É por isso que Lacan nos faz um alerta: não temos como responder aos problemas que o gozo lança ao humano, a não ser pela intensificação dos processos de segregação" (Koltai, 2008, p. 67). Esse aspecto destaca-se no sentido de gozo pela relação com a realização de um desejo que não foi satisfeito socialmente, por esse turno, o desejo de segregar. 
Santos e Vale (2019) discutem essa perspectiva na educação a partir de uma crítica sobre a relevância do aspecto social, entendendo que o sujeito é influenciado em parte pela posição social, porém, o que determina sua relação com o mundo é a interpretação subjetiva e a representação dela, e isso se relaciona com o saber escolar de forma que ele é capaz de modificar e ressignificar o que o mundo fez dele, podendo promover sua libertação do racismo por meio da educação.

Levando em consideração que nessa relação o mais importante é o que o sujeito faz com o que o mundo fez dele, e que ele não é um mero produto, mas também o próprio produtor, que age no e sobre o mundo para adequar-se ou rebelar-se contra o sistema, o sujeito negro pode, mesmo vitimado pelo preconceito racial de diferentes formas, perceber na educação uma possibilidade de ascensão social e/ou pessoal; uma forma de conquistar um espaço de respeito e ter orgulho de sua condição. Desse modo, dependendo de como ele lida com a sua posição social objetiva, ele pode enxergar o racismo como uma barreira passível de ser rompida através do saber escolar (Santos \& Vale, 2019, p. 4).

Santos e Vale (2019) ainda mencionam o papel da mídia frente à educação, pois enquanto a escola tende a ser promovida como um espaço coletivo de construção e acolhimento da diversidade, a mídia realiza a manutenção das desigualdades sociais, o que faz emergir o racismo, pois a sociedade brasileira, racista em si, tende a esconder os preconceitos e a falsidade da democracia racial. Birman (2019) complementa essa análise face à representatividade do racismo na sociedade brasileira:

[...] o Brasil tem suas especificidades, na medida em que aqui se evidencia a presença de signos ostensivos de genocídio da população afrodescendente em consequência da não superação da longa tradição escravocrata, que prevalece, até hoje, com as péssimas condições de saúde e de educação, mas que se fazem também presentes nas populações indígenas. O que implica dizer que existe uma urgência brasileira em face dos impasses colocados para os destinos de tais populações tratadas de forma indigna e que se materializa por laços sociais perversos (Birman, 2019, p. 167-168).

Mais uma vez se resgata a questão social como um elemento limitante da evolução da diversidade e combate ao racismo. Para Munanga (2003, p. 4), é preciso analisar o racismo pelo conceito de identidade para que haja reflexão e mudança na educação brasileira e contexto atual: “O conceito de identidade evoca sempre os conceitos de diversidade, isto é, de cidadania, raça, etnia, gênero, sexo, etc... com os quais ele mantém relações ora dialéticas, ora excludentes, conceitos esses também envolvidos no processo de construção de uma educação democrática". Aqui se explana sobre o quanto a diversidade passa a ser entendida como uma questão de identidade de uma população, que se consolida na educação.

Bernardo e Maciel (2015) investigam a relação entre racismo e educação no ambiente escolar a partir da perspectiva da Lei n. 10.639/2003, que coloca como obrigatório o ensino das culturas afrodescendentes e afrobrasileiras. Para os autores, isso somente se deu em função das demandas sociais de reconhecimento e valorização dos negros na sociedade brasileira, uma vez que converge para a construção da imagem positiva do negro e que pode ser consolidada como inserção da história e memória negras nos livros didáticos e currículos tradicionais, como combate à perspectiva eurocêntrica, que Santos e Machado (2018) afirmam estar presentes nas narrativas literárias utilizadas nas escolas brasileiras, que apresentam uma forma de racismo, de embranquecimento que é recorrente no Brasil e que precisa de revisão em seus conteúdos para que haja desconstrução de modelos estereotipados.

Todavia, essas estratégias não mudam a base de poder nem é um feito de reconstrução política ou social; é apenas uma forma de atender demandas sociais emergentes, ou seja, não se constitui como legitimação da diversidade, não constitui a evolução do racismo à diversidade, mas requer que as bases pelas quais a diversidade foi criada sejam fundamentadas em transformações da subjetividade desses fenômenos. 


\section{Conclusões}

A evolução do racismo à diversidade somente será possível quando houver a evolução do contexto ideológico e cultural de suporte à quebra da segregação nas escolas brasileiras, quando estas passarem a considerar em suas políticas e atividades a importância de se estudar a cultura como intrínseca à evolução das populações, assim como o reconhecimento de que o País é formado de diferenças que não precisam ser negadas ou escondidas, mas que devem ser legitimadas como características da sociedade da qual emergem.

Mostrou-se que a definição de uma identidade para a promoção cultural das diferenças é um caminho para o respeito à diversidade no ambiente escolar, pois esse é um promotor do racismo quando desconsidera a essência cultural dos desiguais, o que os coloca em condição de inferioridade e vitimização perante a sociedade.

A superação de alguns fenômenos psicanalíticos, como a negação, o recalque e o narcisismo emerge como necessária para que haja efetivamente a construção de uma sociedade que respeita integralmente a diversidade. Uma pertinente transformação nos moldes educacionais já é percebida nesse sentido, como sinais de superação de conflitos, mas, também, como tratamento dos problemas psíquicos referentes ao racismo.

Assim, o arcabouço teórico esclarece de forma efetiva quais são os fenômenos sociais e psicanalíticos relacionados com o racismo, e oferece suporte para superar os desafios na educação e garantir a diversidade com parte da cultura que se consolida no ambiente escolar.

Portanto, responde-se ao questionamento de partida e atende-se aos objetivos desta pesquisa, de que a evolução do racismo abarca o contexto social e psicanalítico como forma de construção conjunta de meios para superar as questões psíquicas dos indivíduos, como forma de garantir o respeito da diversidade na educação brasileira e como uma relação possível pela consciência dos fenômenos que sustentam o racismo no País.

O combate ao racismo tem início com o reconhecimento do outro e de suas particularidades, que são distintas a ele, porém podem ser complementares, além da noção de que a diversidade revela traços culturais brasileiros que devem ser legitimados como partes integrantes da cultura e de sua evolução, tendo a educação o papel de consolidar e disseminar as características socioculturais.Contudo, ainda há muito a ser pesquisado nessa perspectiva sobre o racismo e seus desdobramentos na sociedade contemporânea para que se chegue a um ideal de diversidade que abarque a população e sua inserção sociocultural no Brasil. É preciso aprofundar os estudos sobre a subjetividade relativa a esta análise para que, de fato, se possa evoluir do racismo para a diversidade em sua totalidade no contexto da educação.

\section{Referências bibliográficas}

Almeida, S. (2019). Racismo estrutural. São Paulo: Pólen Produção Editorial.

Barros, M. L. de. (2014). "Não somos racistas": uma contrarreação calcada em "a negativa" freudiana. Psicologia Argumento, Curitiba, 32(77), 121-128.

Bento, M. A. S. (2009). Branqueamento e branquitude no Brasil. In M. A. S. Bento, I. Carone (orgs.). Psicologia social do racismo: estudos sobre branquitude e branqueamento no Brasil (4a ed.) (pp. 25-57). Petrópolis, RJ: Vozes.

Bernardo, T., Maciel, R. O. (2015). Racismo e educação: um conflito constante. Contemporânea, 5(1), 191-205.

Birman, J. (2019). Desconstrução do racismo. Revista Latinoamericana de Psicopatologia Fundamental. São Paulo, 22(1), 166-169. 
Domingues, P. J. (2019). Uma história não contada: negro, racismo e branqueamento em São Paulo no pósabolição. São Paulo: Editora Senac.

Dunker, C. I. L. (2004). Formas de apresentação do sofrimento psíquico: alguns tipos clínicos no Brasil contemporâneo. Revista Mal-Estar e Subjetividade, Fortaleza, 4(1), 94-111. Recuperado de http://pepsic.bvsalud.org/scielo.php?script=sci_arttext\&pid=S1518$61482004000100005 \& \operatorname{lng}=p t \& n r m=i s o$.

Freud, S. (2006). Cinco lições de psicanálise, Leonardo da Vinci e outros trabalhos - 1910. Edição standard brasileira das obras psicológicas completas de Sigmund Freud. Rio de Janeiro: Imago.

Gomes, N. L. (2011). Diversidade étnico-racial, inclusão e equidade na educação brasileira: desafios, políticas e práticas. Revista Brasileira de Política e Administração da Educação - RBPAE. Porto Alegre, 27(1), 109-121.

Guareschi, N. M. de F. (2018). Psicologia e diversidade. Psicologia: Ciência e Profissão, 38(3), 409-412.

Henrique, C. (2007). Reconstrução: uma abordagem socio-histórica sobre o racismo à brasileira. Revista Urutágua. Maringá-PR, 12.

Houaiss (s.n.). Dicionário eletrônico para assinantes UOL. Recuperado de https://houaiss.uol.com.br.

IBGE (2019). Instituto Brasileiro de Geografia e Estatística. Projeção da população do Brasil e das Unidades da Federação. Recuperado de https://www.ibge.gov.br/apps/populacao/projecao/.

Koltai, C. (2008). Racismo: uma questão cada vez mais delicada. Ide - Psicanálise e cultura, São Paulo, 31(47), 66-69.

Lacan, J. (1991). O Seminário: Livro 7: a ética da psicanálise. Rio de Janeiro: Jorge Zahar.

Laplanche, J., Pontalis, J. B. (2000). Vocabulário da Psicanálise. São Paulo: Martins Fontes.

Munanga, K. (2003). Diversidade, identidade, etnicidade e cidadania. In 1o Seminário do III Concurso Negro e Educação. São Paulo.

Pereira, J. B. B. (2001). Diversidade, racismo e educação. Revista USP, São Paulo, 50, 169-177.

ROSA, Miriam D. (2004). A pesquisa psicanalítica dos fenômenos sociais e políticos: metodologia e fundamentação teórica. Revista Mal-estar e Subjetividade, Fortaleza, 4(2), 329-348.

Roudinesco E., Plon, M. (1998). Dicionário de psicanálise. Rio de Janeiro: Zahar.

Santos, G. G., Vale, R. A. L. (2019). Racismo na educação escolar. Revista Educação em Questão. Natal, 57(54), 1-23, e-18289.

Santos, J., Machado, R. (2018). A contação de história afro e indígenas na educação infantil. In IV COLBEDUCA e II CIEE, 24 e 25 de Janeiro de 2018, Braga e Paredes de Coura, Portugal.

Silva, D. S., Souza, S. L. (2017). Diversidade sociocultural e relações de poder no Brasil. Revista Labirinto, 26, 281-296.

Esta obra está bajo una Licencia Creative Commons Attribución-NoCommercial 4.0 International

(cc) BY-NC 